\title{
Alternative technique in atypical spinal decompression: the use of the ultrasonic scalpel in paediatric achondroplasia
}

\author{
Timothy Woodacre, Matthew Sewell, Andrew J Clarke, Mike Hutton
}

Department of Spinal Surgery, Trauma and Orthopaedics, Royal Devon and Exeter Hospital, Exeter, Devon, UK

\section{Correspondence to Timothy Woodacre, timothy.woodacre@nhs.net}

Accepted 25 May 2016

\section{SUMMARY}

Spinal stenosis can be a very disabling condition.

Surgical decompression carries a risk of dural tear and neural injury, which is increased in patients with severe stenosis or an atypical anatomy. We present an unusual case of symptomatic stenosis secondary to achondroplasia presenting in a paediatric patient, and highlight a new surgical technique used to minimise the risk of dural and neural injury during decompression.

\section{BACKGROUND}

Achondroplasia is the most common form of disproportionate dwarfism. It is caused by abnormal endochondral bone formation resulting in multiple skeletal abnormalities. ${ }^{1}$ Spine involvement is typical, with early thoracolumbar kyphosis (usually self-resolving), lumbar hyperlordosis, cervicomedullary stenosis and congenital spinal stenosis secondary to shortened pedicles and a decreased interpedicular distance. Symptomatic spinal stenosis commonly occurs in the adult population following further narrowing of the congenitally stenotic canal from disc prolapse or degeneration. ${ }^{2}{ }^{3}$ Symptomatic spinal stenosis is reported in the paediatric achondroplastic population, typically in individuals with excessively narrow interpedicular distance, or persistent thoracolumbar kyphosis. ${ }^{4} 5$ Spinal decompression, with or without instrumentation, has had demonstrable positive results in this patient group. ${ }^{6-9}$

Acute complications of spinal decompression surgery include iatrogenic durotomy with subsequent cerebrospinal fluid leak and nerve root/cauda

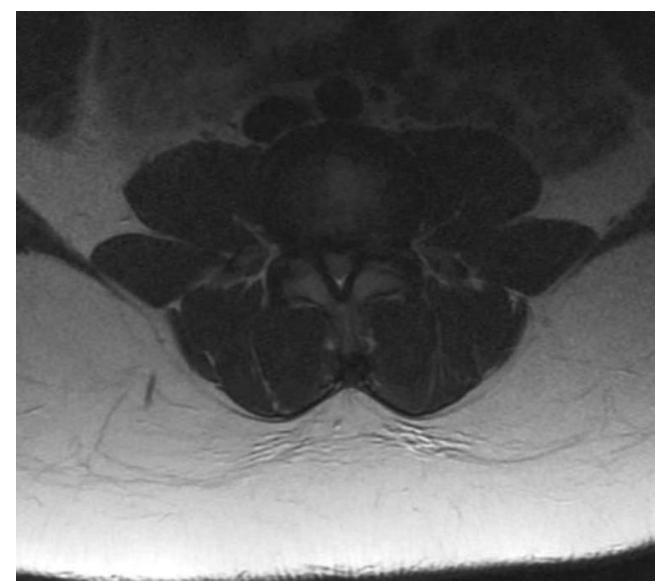

Figure 1 Axial T2-weighted MRI through L3/4. equina/cord injury. Patients with achondroplasia are at potential additional risk due to their differing anatomy, as outlined above, ${ }^{10}$ while paediatric patients with achondroplasia pose a further challenge and complication risk due to their size.

Traditional techniques for posterior decompression of the spinal canal, whether segmentally or via laminectomy, include mechanical bone excision via osteotome or Kerrison forceps, or via high-speed burr. Durotomy or neural injury from direct blunt trauma-soft tissue incision or rotational tearing, respectively-can occur while using these instruments. Recently, ultrasonic bone scalpels have been developed to facilitate precision bone excision while minimising soft tissue damage. These work via longitudinal oscillations of a fine blade at high frequency, facilitating precision cutting of bone through rapid sequential impacts. ${ }^{10}$ Soft tissue absorbs the impact energy of the scalpel due to its elastic nature and is left undamaged. The use of a blunt tip and the absence of any rotational force

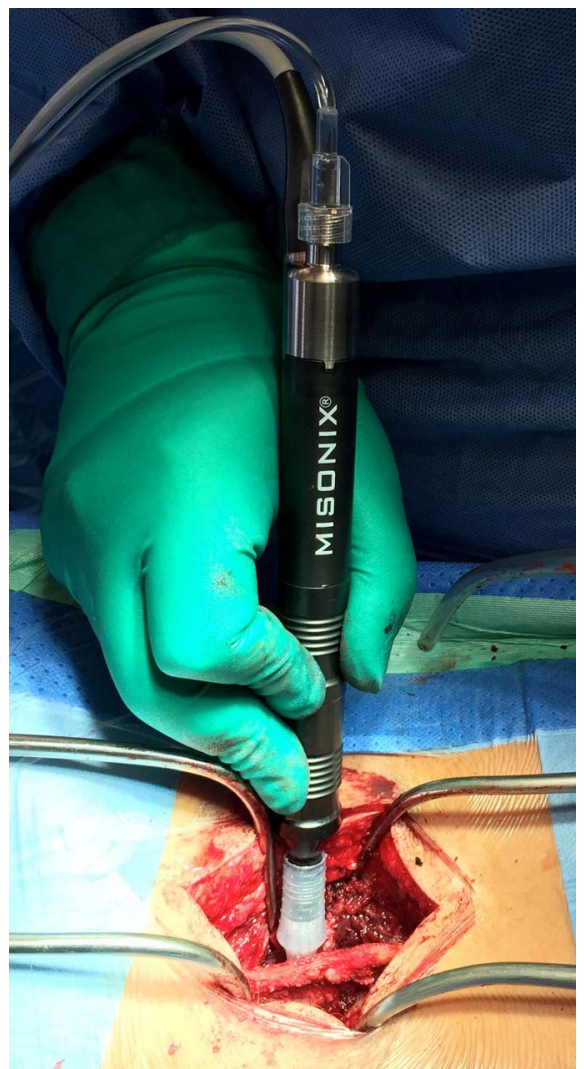

Figure 2 Ultrasonic bone scalpel in use. 
minimises the risk of soft tissue cutting and tearing that can occur with sharp Kerrison forceps and burrs. The smaller kerf size ( $\sim 0.5 \mathrm{~mm}$ ultrasonic scalpel vs $2-3 \mathrm{~mm}$ burr or osteotome) and smaller tip displacement allow for higher precision cutting and the higher cutting frequency (22 500 strokes/second vs $\sim 1300$ repetitions/second of a burr) allows for more rapid cutting. ${ }^{11}$ The ultrasonic bone scalpel is therefore of potential use in patients undergoing challenging spinal decompression where neural injury is of increased risk, such as in the achondroplastic population. We report the use of the ultrasonic scalpel in the decompression of a challenging paediatric patient with achondroplasia.

\section{CASE PRESENTATION}

We describe a case of a 15 -year-old boy with achondroplasia who presented with 14 months of severe stenotic symptoms with bilateral leg pain, heaviness and numbness after mobilising short distances, eased on rest and sitting. This deteriorated with time, with symptoms developing after $3 \mathrm{~min}$ of walking, all sporting activities being stopped and subsequent increase in weight.

\section{INVESTIGATIONS}

MRI revealed severe central canal and lateral recess stenosis at L2/3 and L3/4 (figure 1), with likely asymptomatic lateral recess stenosis at L4/5 and L5/S1. An erect radiograph demonstrated no spondylolisthesis under physiological load.

\section{TREATMENT}

The patient underwent primary decompression alone. This was achieved via posterior midline incision, laminotomy, flavectomy and partial medial facetectomy, at L2 and L3. All bone dissection was completed via an ultrasonic bone scalpel. Rapid bone dissection was achieved with ease-the laminotomy was performed with controlled $0.5 \mathrm{~mm}$ lateral troughs (figures 2 and 3); there
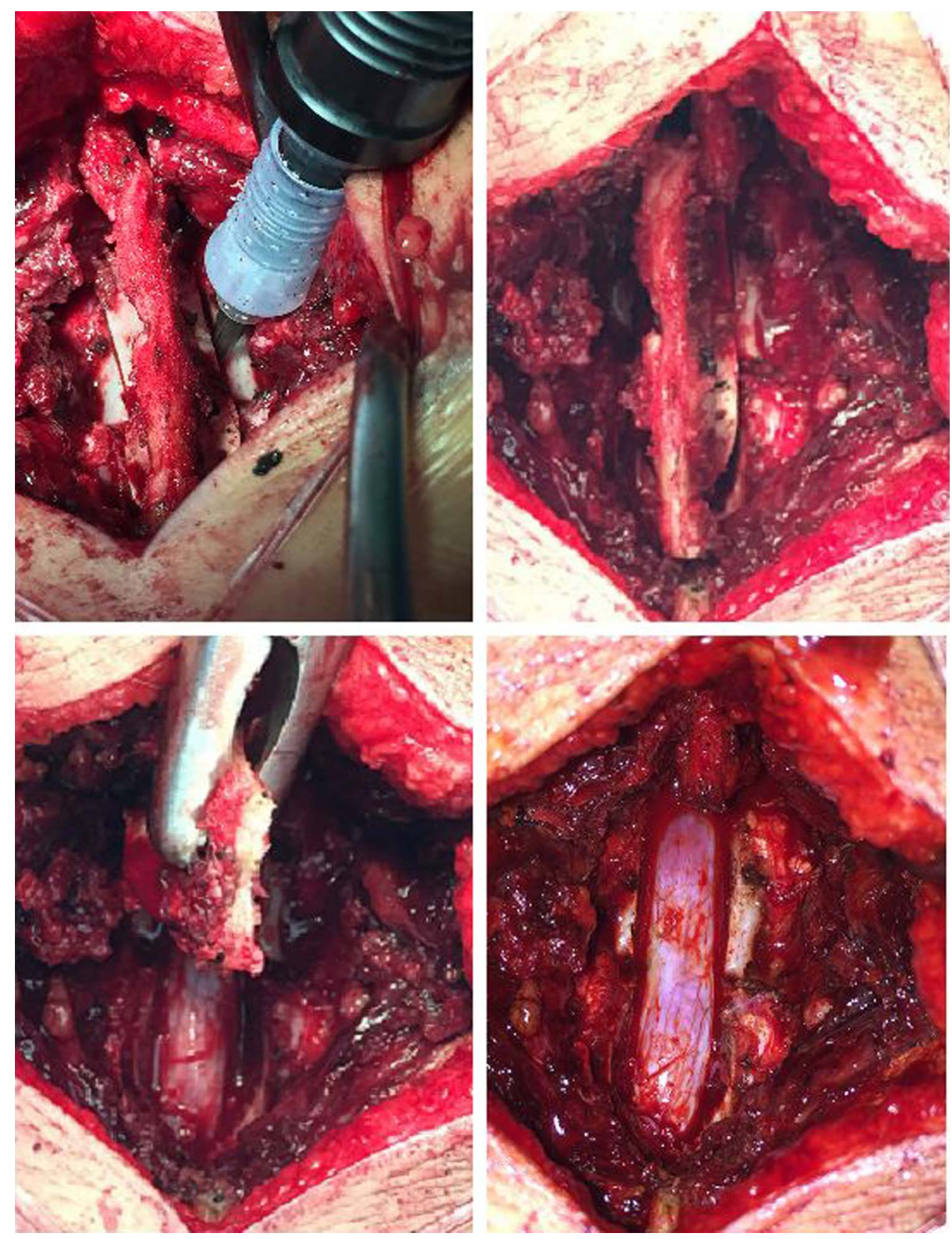

Figure 3 Ultrasonic bone scalpel en bloc laminectomy. 
was no iatrogenic dural tear, and neither nerve root nor cauda equina injury.

\section{OUTCOME AND FOLLOW-UP}

The patient was mobilised and discharged on day 1 postoperatively and suffered no subsequent complications. Follow-up 6 months postoperatively revealed clinical resolution of stenotic symptoms and full return to symptom-free sporting activities.

\section{DISCUSSION}

The use of the ultrasonic bone scalpel in spinal surgery has been reported in the literature. Parker et $a l^{12}$ analysed 40 adult patients without achondroplasia undergoing laminoplasty utilising an ultrasonic bone scalpel. They recorded one case of incidental durotomy following use of the ultrasonic scalpel, and concluded that it was a safe and technically feasible device for use in adult laminoplasty. Sanborn et $a l^{13}$ reached a similar conclusion in ovine laminectomies, but also demonstrated neither neurophysiological nor clinical differences between groups where the ultrasonic bone scalpel was used versus traditional high speed burrs, but with improved local tissue repair and shorter operative time in the bone scalpel group. Onen et al ${ }^{14}$ analysed 46 adult patients without achondroplasia undergoing cervical laminectomy, comparing the use of an ultrasonic bone scalpel $(n=23)$ to a high-speed burr $(n=23)$. They demonstrated decreased laminectomy time $(2.2 \pm 0.4$ vs $7.4 \pm 2.6 \mathrm{~min} / \mathrm{level})$, blood loss $(180$ vs $380 \mathrm{cc})$, time in hospital $(3.0 \pm 0$ vs 3.7 \pm 1.3 days) and complications (1 C5 radiculopathy vs 1 C5 radiculopathy and 3 dural injuries) when using the bone scalpel in preference to the high-speed burr; concluding that it was safe and effective in cervical laminectomy. Lieberman and $\mathrm{Hu}^{15}$ assessed 58 consecutive spinal surgeries with a variety of pathology (scoliosis, kyphosis and spondylolisthesis) and noted subjectively minimal bone bleeding from the osteotomy sights;

Learning points

- Spinal stenosis is a clinical problem typically occurring from facet joint degeneration and flavum hypertrophy.

- Alternative aetiology includes congenital stenosis in patients with achondroplasia, typically presenting in a younger population.

- Surgical decompression carries a risk of a dural tear and a rare risk of neural injury, which is increased in severe or atypical cases.

- The use of an ultrasonic bone scalpel is a new technique that provides a safe and effective option for neural decompression in difficult and atypical cases, such as in a paediatric patient with congenital stenosis secondary to achondroplasia. however, they did note one $3 \mathrm{~mm}$ dural thermal injury from the ultrasonic bone scalpel remaining in one place for too long.

The ultrasonic bone scalpel has therefore been published as an efficient tool when used in standard adult lumbar/cervical posterior surgical decompression, providing rapid bone dissection with minimal risk to the dura. We describe a case involving challenging stenosis in a paediatric patient with achondroplasia and demonstrate effective and safe decompression using the ultrasonic scalpel.

The ultrasonic bone scalpel is a more expensive tool than other options for spinal decompression (surgical burr or Kerrison forceps). Our department utilises an ultrasonic scalpel from Neurotechnics. The requirement for a disposable blade, one used per patient, places an estimated equipment cost of $£ 400$ per case ( $\sim 40$ times the cost of a surgical diamond burr). Our department therefore reserves the use of the ultrasonic bone scalpel for rare patients with extremely complex spinal stenosis with an associated high risk of dural injury, but finds it an invaluable adjunct, such as in the case described.

Competing interests None declared.

\section{Patient consent Obtained.}

Provenance and peer review Not commissioned; externally peer reviewed.

\section{REFERENCES}

1 Oberklaid F, Danks DM, Jensen F, et al. Achondroplasia and hypochondroplasia: comments on frequency, mutation rate, and radiological features in skull and spine. J Med Genet 1979;16:140-6.

2 Epstein JA, Malis LI. Compression of spinal cord and cauda equina in achondroplastic dwarfs. Neurology 1955;5:875-81.

3 Tolo V. Spinal disorders associated with skeletal dysplasias and metabolic diseases. In: Rothman RH, Simeone FA, eds. The spine. Vol 1. 3rd edn. Philadelphia: W.B. Saunders Company, 1992:349-64.

4 Schkrohowsky JG, Hoernschemeyer DG, Carson BS, et al. Early presentation of spinal stenosis in achondroplasia. J Pediatr Orthop 2007;27:119-22.

5 Hecht JT, Butler IJ. Neurologic morbidity associated with achondroplasia. J Child Neurol 1990;5:84-97.

6 Sciubba DM, Noggle JC, Marupudi NI, et al. Spinal stenosis surgery in pediatric patients with achondroplasia. J Neurosurg 2007;106(5 Suppl):372-8.

7 Baca KE, Abdullah MA, Ting BL, et al. Surgical decompression for lumbar stenosis in pediatric achondroplasia. J Pediatr Orthop 2010;30:449-54.

8 Fortuna A, Ferrante L, Acqui M, et al. Narrowing of thoraco-lumbar spinal canal in achondroplasia. J Neurosurg Sci 1989;33:185-96.

9 Iliescu B, Gaivas S, Apetrei C, et al. Severe spinal stenosis in adult achondroplastic dwarf-case report. Rom Neurosurg 2010;XVII 4:445-8.

10 Schmidek HH, Sweet WH. Operative neurosurgical techniques, indications, methods and results. Vol 2. 6th edn. Saunders, Elsevier Inc, 2012:2091-100.

11 Neurotechnics: Bone scalpel: ultra sonic bone cutting. Retrieved from the World Wide Web on 21/09/2015. http://www.neuro-technics.com/products/neurotechnics/ bonescalpel/

12 Parker SL, Kretzer RM, Recinos PF, et al. Ultrasonic bone scalpel for osteoplastic laminoplasty in the resection of intradural spinal pathology: case series and technical note. Neurosurgery 2013;73(1 Suppl Operative):ons61-6.

13 Sanborn MR, Balzer J, Gerszten PC, et al. Laboratory study: safety and efficacy of a novel ultrasonic osteotome device in an ovine model. J Clin Neurosci 2011;18:1528-33.

14 Onen MR, Yuvruk E, Akay S, et al. The reliability of the ultrasonic bone scalpel in cervical spondylotic myelopathy: a comparative study of 46 patients. World Neurosurg 2015;84:1962-7.

15 Lieberman $\mathrm{IH}, \mathrm{Hu} X$. Use of ultrasonic bone scalpel in spine surgeries: experience from the first 58 patients. 19th International Meeting on Advanced Spine Techniques. Istanbul, Turkey, 2012. 
Copyright 2016 BMJ Publishing Group. All rights reserved. For permission to reuse any of this content visit http://group.bmj.com/group/rights-licensing/permissions.

BMJ Case Report Fellows may re-use this article for personal use and teaching without any further permission.

Become a Fellow of BMJ Case Reports today and you can:

- Submit as many cases as you like

- Enjoy fast sympathetic peer review and rapid publication of accepted articles

- Access all the published articles

- Re-use any of the published material for personal use and teaching without further permission

For information on Institutional Fellowships contact consortiasales@bmjgroup.com

Visit casereports.bmj.com for more articles like this and to become a Fellow 